\title{
Cardiac arrest induced by the intentional ingestion of boric acid and mirtazapine treated by percutaneous cardiopulmonary bypass: a case report
}

Hiroki Nagasawa ${ }^{1}$, Hiroaki Nakanishi ${ }^{2}$, Kazuyuki Saito ${ }^{2}$, Takehisa Matsukawa ${ }^{3}$, Kazuhito Yokoyama ${ }^{3}$ and Youichi Yanagawa ${ }^{1 *}$

\begin{abstract}
Background: Mirtazapine has a good tolerability and safety profile that demonstrates several benefits over other antidepressants and it is associated with few fatalities. Boric acid is an odorless white powder that is generally not recognized as a poisonous substance. We report a case of cardiac arrest induced by the intentional ingestion of mirtazapine, boric acid, and sennosides, by a patient who required percutaneous cardiopulmonary bypass.

Case presentation: Our patient was a 49-year-old Japanese woman with a history of depression; she was found in an unconscious state after ingesting boric acid (unknown amount), mirtazapine (1950 mg), and sennosides (780 mg). On arrival, she was in a deep coma with marked hypotension induced by atrial fibrillation, tachycardia, and diffuse hypokinetic cardiac motion. She had systemic diffuse erythema. Her serum concentrations of boric acid and mirtazapine on arrival were $560.49 \mathrm{mg} / \mathrm{L}$ and $1270 \mathrm{ng} / \mathrm{mL}$, respectively. She experienced repeated cardiac arrest, and was therefore treated with tracheal intubation, mechanical ventilation, percutaneous cardiopulmonary bypass, and continuous hemodialysis filtration. Stable circulation and respiration and a normal kidney function were finally obtained and she was transferred to a local medical facility in a persistent unconscious state.

Conclusions: This is the first case of a return of spontaneous circulation after cardiac arrest induced by the intentional ingestion of boric acid and mirtazapine, requiring percutaneous cardiopulmonary bypass for survival. To maintain cerebral perfusion during percutaneous cardiopulmonary bypass, even in a prolonged state of cardiac arrest induced by overdose, is medically, ethically, and economically challenging.
\end{abstract}

Keywords: Boric acid, Mirtazapine, Percutaneous cardiopulmonary bypass

\section{Background}

Mirtazapine is a noradrenergic and specific serotoninergic antidepressant agent that stimulates the release of norepinephrine and serotonin while also blocking serotonin receptors, that is, 5-hydroxytryptamine $2\left(5-\mathrm{HT}_{2}\right)$ and 5-hydroxytryptamine $3\left(5-\mathrm{HT}_{3}\right)$ [1]. Mirtazapine has a good tolerability and safety profile that demonstrates several benefits over other antidepressants and it is associated with few fatalities $[1,2]$. Boric acid is an odorless

\footnotetext{
* Correspondence: yyanaga@juntendo.ac.jp

${ }^{1}$ Department of Acute Critical Care Medicine, Shizuoka Hospital, Juntendo

University, 1129 Nagaoka, Izunokuni City, Shizuoka 410-2295, Japan

Full list of author information is available at the end of the article
}

white powder that is generally not recognized as a poisonous substance. However, if ingested in massive quantities, boric acid can have potentially fatal effects, including metabolic acidosis, acute renal failure, and heart failure $[3,4]$.

Percutaneous cardiopulmonary bypass or extracorporeal membrane oxygenation is an external approach that supports the cardiopulmonary system by providing oxygenation and ensuring the cardiac function of patients with cardiac and respiratory failure. Percutaneous cardiopulmonary bypass has been successfully used in patients of all ages with various medical and surgical conditions leading to cardiovascular collapse, respiratory

(c) The Author(s). 2019 Open Access This article is distributed under the terms of the Creative Commons Attribution 4.0 International License (http://creativecommons.org/licenses/by/4.0/), which permits unrestricted use, distribution, and 
failure, cardiogenic shock, or refractory hypotension [5]. Extracorporeal membrane oxygenation has also been used in cases of poisoning when cardiac arrest or refractory hypotension develops, although such instances are rare [5].

We feel it is important to accumulate more reports on toxicology cases treated with percutaneous cardiopulmonary bypass [5-12]. Accordingly, we report a case of cardiac arrest induced by the intentional ingestion of mirtazapine, boric acid, and sennosides by a patient who required percutaneous cardiopulmonary bypass.

\section{Case presentation}

Local Institutional Review Board approval was obtained, and the patient's guardian gave their written, informed consent to publish this case.

A 49-year-old Japanese woman with a history of depression was found in an unconscious state by her husband after ingesting an unknown amount of boric acid, mirtazapine $(1950 \mathrm{mg})$, and sennosides $(780 \mathrm{mg}$ ) and transported to a local medical facility. She had unstable circulation so she was transported to our Department of Acute Critical Care Medicine. On arrival, her vital signs were as follows: Glasgow Coma Scale, E1V1M1; blood pressure, $45 / 13 \mathrm{mmHg}$; heart rate, 190 beats per minute; and body temperature, $37.0^{\circ} \mathrm{C}$. She had systemic diffuse erythema. There were no other physical findings. Electrocardiography (ECG) showed atrial fibrillation tachycardia. She received tracheal intubation with mechanical ventilation. A cardiac echocardiogram depicted diffuse hypokinesis of wall motion with an ejection fraction of $20 \%$. Chest roentgenography revealed no findings. Whole-body computed tomography to evaluate her brain condition, residual drugs in her stomach, and accompanying lesions indicated bilateral dorsal lung consolidation, suggesting aspiration [13]. The results of an arterial blood gas analysis, cell blood count, and biochemical study are shown in Table 1. Soon after, she exhibited pulseless electrical activity; spontaneous circulation was obtained by advanced life support. However, she experienced repeated episodes of pulseless electrical activity, and percutaneous cardiopulmonary bypass was required due to unstable circulation. An emergency coronary angiogram was negative. She was admitted to an intensive care unit and underwent additional continuous hemodialysis filtration due to acute kidney injury with anuria. She

Table 1 The results of the laboratory analysis

\begin{tabular}{|c|c|c|c|}
\hline \multicolumn{4}{|l|}{ Arterial blood gas (10 L/minute oxygen) } \\
\hline $\mathrm{pH}$ & 7.499 & $\mathrm{PCO}_{2}$ & $41.6 \mathrm{mmHg}$, \\
\hline $\mathrm{PO}_{2}$ & $429 \mathrm{mmHg}$ & $\mathrm{HCO}_{3}^{-}$ & $32.1 \mathrm{mmol} / \mathrm{l}$ \\
\hline Base excess & $8.4 \mathrm{mmol} / \mathrm{l}$ & Lactate & $10.7 \mathrm{mmol} / \mathrm{l}$ \\
\hline \multicolumn{4}{|l|}{ Cell blood count } \\
\hline White blood cell count & $12,900 / \mu l$ & Hemoglobin & $6.0 \mathrm{~g} / \mathrm{dl}$ \\
\hline Red blood cell count & $330 \times 10^{4} / \mu l$ & Hematocrit & $20 \%$ \\
\hline Platelet count & $37.8 \times 10^{4} / \mu l$ & & \\
\hline \multicolumn{4}{|l|}{ Serum biochemistry } \\
\hline Total protein & $6.3 \mathrm{~g} / \mathrm{dl}$ & Albumin & $3.3 \mathrm{~g} / \mathrm{dl}$ \\
\hline Total bilirubin & $0.5 \mathrm{mg} / \mathrm{dl}$ & Cholinesterase & $176 \mathrm{IU} / \mathrm{L}$ \\
\hline Aspartate aminotransferase & $20 \mathrm{IU} / \mathrm{I}$ & Alanine aminotransferase & $7 \mathrm{U} / \mathrm{l}$ \\
\hline Y-glutamyl transpeptidase & $9 \| / L$ & Alkaline phosphatase & $159 \mathrm{IU} / \mathrm{L}$ \\
\hline Creatine phosphokinase & $307 \mathrm{IU} / \mathrm{l}$ & Amylase & $74 \mathrm{IU} / \mathrm{L}$ \\
\hline Blood urea nitrogen & $32 \mathrm{mg} / \mathrm{dl}$ & Creatinine & $3.0 \mathrm{mg} / \mathrm{dl}$ \\
\hline Glucose & $168 \mathrm{mg} / \mathrm{dl}$ & $\mathrm{HbA}_{1} \mathrm{C}$ & $5.8 \%$ \\
\hline Sodium & $152 \mathrm{mEq} / \mathrm{l}$ & Potassium & $2.5 \mathrm{mEq} / \mathrm{l}$ \\
\hline Chloride & $104 \mathrm{mEq} / \mathrm{l}$ & C reactive protein & $1.1 \mathrm{mg} / \mathrm{dl}$ \\
\hline Ammonia & $53 \mu \mathrm{g} / \mathrm{dL}$ & & \\
\hline \multicolumn{4}{|l|}{ Coagulation } \\
\hline Activated partial thromboplastin time & 29 (24.9) seconds & & \\
\hline Prothrombin time & 21 (12.1) seconds & & \\
\hline Fibrinogen & 195 mg/dl & & \\
\hline Fibrinogen degradation products & $3.3 \mu \mathrm{g} / \mathrm{mL}$ & & \\
\hline
\end{tabular}

$\mathrm{HbA}_{1} \mathrm{C}$ glycated hemoglobin, $\mathrm{HCO}_{3}^{-}$bicarbonate, $p \mathrm{CO}_{2}$ partial pressure of carbon dioxide, $p \mathrm{O}_{2}$ partial pressure of oxygen 
remained in a deep coma state without sedation. On the second hospital day, cardiac motion ceased on the echocardiogram, but her atrial fibrillation rhythm continued. As her husband strongly wished to continue these treatments, we selected to continue them until cardiac standstill. However, cardiac motion was obtained again on the fourth hospital day and stable spontaneous circulation with sinus rhythm was obtained on the sixth hospital day; thus, percutaneous cardiopulmonary bypass was withdrawn. She exhibited hair loss. She remained in a persistent unconscious state; thus, tracheostomy was performed on the seventh hospital day. Sufficient urinary flow was obtained, and her potassium level remained within the normal limits; thus, continuous hemodialysis filtration was withdrawn on the tenth hospital day. Head magnetic resonance imaging showed signal change in the bilateral white matter and caudate nuclei, suggesting hypoperfusional cerebral ischemia. As she developed right leg dry necrosis, which was induced by cannulation for percutaneous cardiopulmonary bypass, leg amputation was performed on the 22nd hospital day. She also developed bilateral corneal ulcers, which was possibly due to boric acid poisoning.

Stable spontaneous respiration was finally obtained on the 30th hospital day; thus, mechanical ventilation was withdrawn. Systemic erythema gradually subsided with desquamation. She displayed spontaneous eye opening and spontaneous movement of her extremities; however, she could not respond to any commands. She was transferred to a local medical facility in a persistent unconscious state on the 39th hospital day. A subsequent examination revealed that her serum concentrations of boric acid and mirtazapine on arrival were $560.49 \mathrm{mg} / \mathrm{L}$ and $1270 \mathrm{ng} / \mathrm{mL}$, respectively (Fig. 1). She could speak simple words for commands and swallow food but was unable to walk; thus, at 6 months after collapse, she was totally dependent in her activities of daily living.

\section{Discussion}

This is the first case of cardiac arrest induced by the intentional ingestion of boric acid and mirtazapine, in which percutaneous cardiopulmonary bypass was required for the patient to survive.

With regard to cardiotoxicity, Leonard et al. [14] investigated the association between exposure to antidepressants and emergency department or in-patient admission for sudden cardiac death and ventricular arrhythmia (SD/VA). Among 1.3 million person-years of antidepressant exposure, they identified 4222 SD/VA outcomes, which amounted to a rate of 3.3/1000 person-years (95\% CI, 3.2-3.4). In comparison to paroxetine (a referent with a reportedly favorable cardiovascular risk profile), the adjusted hazard ratio (HR) for mirtazapine was 1.26 (1.11-1.42). They concluded that of the antidepressants that were studied, only mirtazapine had a statistically significantly greater SD/VA risk than paroxetine. A massive ingestion of boric acid generally induces metabolic acidosis, renal failure, and skin disturbance. However, boric

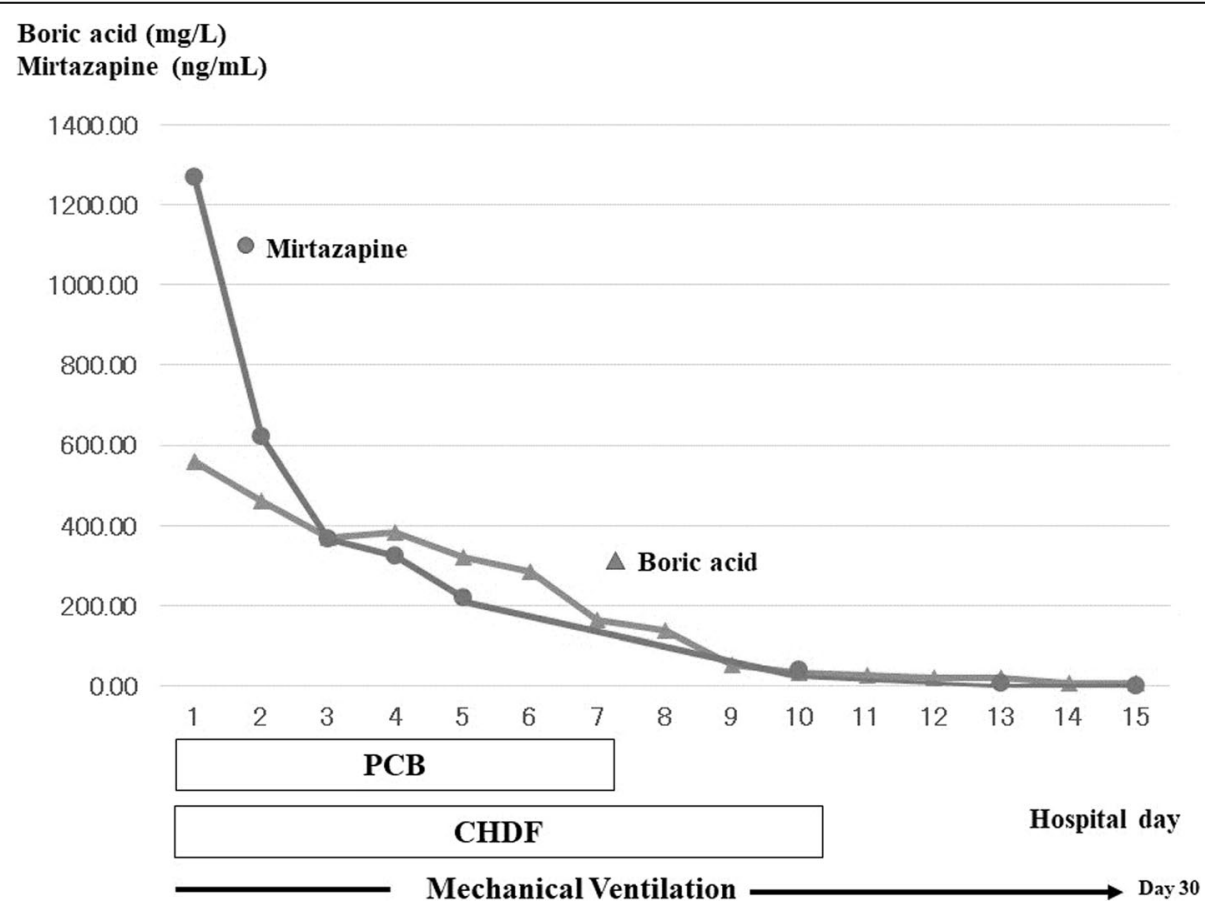

Fig. 1 The time course of the serum concentrations of boric acid and mirtazapine. The initial levels of boric acid and mirtazapine were 560.49 $\mathrm{mg} / \mathrm{L}$ and $1270 \mathrm{ng} / \mathrm{mL}$, respectively. CHDF continuous hemodiafiltration, PCB percutaneous cardiopulmonary support 
acid can also induce lethal arrhythmia and cardiac failure $[3,4]$. Accordingly, both boric acid and mirtazapine could have caused fatal cardiac arrest due to direct cardiac intoxication in this case. Regarding the toxic effects of sennosides in laboratory animals, the lethal dose 50 value was approximately $5000 \mathrm{mg} / \mathrm{kg}$, and the cause of death was extensive water and electrolyte loss following massive diarrhea [15]. However, the patient in the present case did not ingest a fatal dose and dehydration was not observed; thus, the possibility that sennosides were involved in the patient's cardiac arrest could be denied.

Percutaneous cardiopulmonary bypass may be helpful in cases of exposure to multiple serious toxicological agents that results in temporary cardiorespiratory failure or metabolic dysfunction. Percutaneous cardiopulmonary bypass alone does not remove or neutralize any toxins but does provide hemodynamic support and oxygenation until the toxins can be eliminated or end-organ recovery is achieved. A case series of 62 patients in France showed similar survival rates of $76 \%$ in patients receiving percutaneous cardiopulmonary bypass due to severe acute drug intoxication, with a lower overall mortality rate than in patients who received supportive care alone $[16,17]$. The cardiotoxic effects of antidepressants are reported to be temporary, and there have been some cases in which patients who have exhibited unstable circulation due to overdose have also achieved social rehabilitation after percutaneous cardiopulmonary bypass treatment $[18,19]$. The present case also demonstrated that the cardiotoxicity induced by the massive ingestion of mirtazapine and boric acid was a temporary effect.

However, whether or not percutaneous cardiopulmonary bypass can improve the survival in patients with cardiac arrest due to toxicological agent exposure remains unclear. Attempting to initiate percutaneous cardiopulmonary bypass during cardiac arrest is difficult, as it may require pausing cardiopulmonary resuscitation in order to cannulate and initiate the procedure, which may result in an unfavorable outcome. In addition, thoracic cage injury induced by chest compression may result in fatal complications due to coagulopathy after the initiation of percutaneous cardiopulmonary bypass, requiring heparinization [20]. Furthermore, our attempt to use percutaneous cardiopulmonary bypass to obtain social rehabilitation failed due to hypoperfusional cerebral ischemia induced by prolonged cardiac arrest, which has also been reported in patients who underwent percutaneous cardiopulmonary bypass after experiencing cardiac arrest triggered by other causes [21].

The indication of percutaneous cardiopulmonary bypass for poisoned patients remains a major problem. First, substantial resources and costs as well as a multidisciplinary team including toxicologists, intensivists, and surgeons, are required to perform and manage percutaneous cardiopulmonary bypass, so few facilities are equipped to activate it in a timely fashion [5]. Second, percutaneous cardiopulmonary bypass is associated with a number of potential complications, including limb ischemia, compartment syndrome, cerebral ischemia, acute kidney injury, bleeding, emboli, and infection [5]. Third, several factors must be considered on an individual basis, such as the patient's age, comorbidities, risk for complications, survivability, specific drug or chemical involved in the exposure, and time of hypoperfusion or cardiac arrest [5]. Accordingly, further studies are needed in order to establish criteria for considering percutaneous cardiopulmonary bypass in poisoned patients.

\section{Conclusion}

This is the first case in which a return of spontaneous circulation was obtained after cardiac arrest induced by the intentional ingestion of boric acid and mirtazapine, in a patient who required percutaneous cardiopulmonary bypass for survival. The present case demonstrated that the cardiotoxicity induced by the massive ingestion of mirtazapine and boric acid was a temporary effect. To maintain cerebral perfusion during percutaneous cardiopulmonary bypass, even in cases involving prolonged cardiac arrest induced by overdose, is medically, ethically, and economically challenging.

\section{Abbreviations \\ 5- $\mathrm{HT}_{2}$ : 5-Hydroxytryptamine $2 ; 5-\mathrm{HT}_{3}$ : 5-Hydroxytryptamine : $_{3}$ \\ ECG: Electrocardiography; HR: Hazard ratio; SDNA: Sudden cardiac death and ventricular arrhythmia}

\section{Acknowledgements \\ None.}

\section{Funding}

This manuscript obtains financial support from the Ministry of Education, Culture, Sports, Science and Technology (MEXT)-Supported Program for the Strategic Research Foundation at Private Universities, 2015-2019 concerning [The constitution of total researching system for comprehensive disaster, medical management, corresponding to wide-scale disaster].

\section{Availability of data and materials \\ None.}

Authors' contributions

YY provided medicine for the patient and edited the draft of the manuscript. HNak, KS, TM, and KY provided drug analysis. HNag and YY provided medicine for the patient and wrote the manuscript as a corresponding author. All authors read and approved the final manuscript.

Ethics approval and consent to participate

The study was approved by our institutional ethics committee (Juntendo Igakugu Fuzoku Shizuoka Byouin Rinrishinnsa linkai). Reference number is 298.

\section{Consent for publication}

Written informed consent was obtained from the patient's husband for publication of this case report and any accompanying images. A copy of the written consent is available for review by the Editor-in-Chief of this journal.

Competing interests

The authors declare that they have no competing interests. 


\section{Publisher's Note}

Springer Nature remains neutral with regard to jurisdictional claims in published maps and institutional affiliations.

\section{Author details}

'Department of Acute Critical Care Medicine, Shizuoka Hospital, Juntendo University, 1129 Nagaoka, Izunokuni City, Shizuoka 410-2295, Japan. ${ }^{2}$ Department of Forensic Medicine, Juntendo University, Tokyo, Japan. ${ }^{3}$ Department of Epidemiology and Environmental Health, Juntendo University, Tokyo, Japan.

Received: 10 January 2019 Accepted: 11 April 2019

Published online: 16 May 2019

\section{References}

1. Vignali C, Groppi A, Brandolini F, Avato FM, Talarico A, Gaudio RM, Morini L. Mirtazapine fatal poisoning. Forensic Sci Int. 2017;276:e8-e12.

2. Salomone A, Di Corcia D, Gerace E, Vincenti M. A fatal case of simultaneous ingestion of mirtazapine, escitalopram, and valproic acid. J Anal Toxicol. 2011;35:519-23.

3. Restuccio A, Mortensen ME, Kelley MT. Fatal ingestion of boric acid in an adult. Am J Emerg Med. 1992;10:545-7.

4. Ishii Y, Fujizuka N, Takahashi T, Shimizu K, Tuchida A, Yano S, Naruse T, Chishiro T. A fatal case of acute boric acid poisoning. J Toxicol Clin Toxicol. 1993;31:345-52.

5. Wang GS, Levitan R, Wiegand TJ, Lowry J, Schult RF, Yin S. Toxicology Investigators Consortium. Extracorporeal Membrane Oxygenation (ECMO) for Severe Toxicological Exposures: Review of the Toxicology Investigators Consortium (ToxIC). J Med Toxicol. 2016;12:95-9.

6. Nordmark Grass J, Ahlner J, Kugelberg FC, Steinwall J, Forsman P, Lindeman E. A case of massive metoprolol and amlodipine overdose with blood concentrations and survival following extracorporeal corporeal membrane oxygenation (ECMO). Clin Toxicol (Phila). 2019;57:66-8.

7. Chenoweth JA, Colby DK, Sutter ME, Radke JB, Ford JB, Nilas Young J, Richards JR. Massive diltiazem and metoprolol overdose rescued with extracorporeal life support. Am J Emerg Med. 2017;35:1581.e3-5.

8. Heise CW, Skolnik AB, Raschke RA, Owen-Reece H, Graeme KA. Two Cases of Refractory Cardiogenic Shock Secondary to Bupropion Successfully Treated with Veno-Arterial Extracorporeal Membrane Oxygenation. J Med Toxicol, 2016;12:301-4

9. Hassanian-Moghaddam H, Zamani N, Rahimi M, Hajesmaeili M, Taherkhani M, Sadeghi R. Successful Treatment of Aluminium Phosphide Poisoning by Extracorporeal Membrane Oxygenation. Basic Clin Pharmacol Toxicol. 2016; 118:243-6.

10. Escajeda JT, Katz KD, Rittenberger JC. Successful treatment of metoprololinduced cardiac arrest with high-dose insulin, lipid emulsion, and ECMO. Am J Emerg Med. 2015;33:1111. e1-4

11. Heise CW, Beutler D, Bosak A, Orme G, Loli A, Graeme K. Massive Atenolol, Lisinopril, and Chlorthalidone Overdose Treated with Endoscopic Decontamination, Hemodialysis, Impella Percutaneous Left Ventricular Assist Device, and ECMO. J Med Toxicol. 2015;11:110-4

12. Kan'o T, Kamijo Y, Hattori J, Kashimi F, Sato C, Yoshimura K. Refractory status epilepticus, circulatory collapse after cardiac arrest, and acute respiratory distress syndrome caused by severe isolated fluvoxamine poisoning: a case report. Acute Med Surg. 2014;2:53-5.

13. Yanagawa Y, Nishi K, Imamura T, Sakamoto T. Usefulness of computed tomography in the diagnosis of an overdose. Acta Med Okayama. 2011;65:33-9.

14. Leonard CE, Bilker WB, Newcomb C, Kimmel SE, Hennessy S. Antidepressants and the risk of sudden cardiac death and ventricular arrhythmia. Pharmacoepidemiol Drug Saf. 2011;20:903-13.

15. Mengs $U$. Toxic effects of sennosides in laboratory animals and in vitro. Pharmacology. 1988;36(Suppl 1):180-7.

16. Shenoi AN, Gertz SJ, Mikkilineni S, Kalyanaraman M. Refractory hypotension from massive bupropion overdose successfully treated with extracorporeal membrane oxygenation. Pediatr Emerg Care. 2011;27:43-5.

17. Johnson NH, Gaieski DF, Allen SR, Perrone J, DeRoos F. A review of emergency cardiopulmonary bypass for severe poisoning by cardiotoxic drugs. J Med Toxicol. 2013;99:54-60.

18. Abeyaratne DD, Liyanapathirana C, Gamage A, Karunarathne P, Botheju M, Indrakumar J. Survival after severe amitriptyline poisoning with prolonged ventricular tachycardia and cardiac arrest. BMC Res Notes. 2016;9:167.
19. Holzer M, Sterz F, Schoerkhuber W, Behringer W, Domanovits H, Weinmar D, Weinstabl C, Stimpfl T. Successful resuscitation of a verapamil-intoxicated patient with percutaneous cardiopulmonary bypass. Crit Care Med. 1999;27: 2818-23.

20. Yamagishi T, Kashiura M, Sugiyama K, Nakamura K, Ishida T, Yukawa T, Miyazaki K, Tanabe T, Hamabe Y. Chest compression-related fatal internal mammary artery injuries manifesting after venoarterial extracorporeal membrane oxygenation: a case series. J Med Case Rep. 2017;11:318.

21. Zeliaś A, Stępińska J, Andres J, Trąbka-Zawicki A, Sadowski J, Żmudka K. Tenyear experience of an invasive cardiology centre with out-of-hospital cardiac arrest patients admitted for urgent coronary angiography. Kardiol Pol. 2014;72:687-99.

\section{Ready to submit your research? Choose BMC and benefit from:}

- fast, convenient online submission

- thorough peer review by experienced researchers in your field

- rapid publication on acceptance

- support for research data, including large and complex data types

- gold Open Access which fosters wider collaboration and increased citations

- maximum visibility for your research: over $100 \mathrm{M}$ website views per year

At BMC, research is always in progress.

Learn more biomedcentral.com/submissions 